\title{
The Dilemma of Road Traffic Accidents in Iran
}

\author{
Mohammad Meskarpour Amiri ${ }^{1}$, Mohammadkarim Bahadori ${ }^{1,}$, Ali Mehrabi-Tavana ${ }^{1}$ \\ ${ }^{1}$ Health Management Research Center, Baqiyatallah University of Medical Sciences, Tehran, Iran
}

Corresponding Author: Mohammadkarim Bahadori, Associate Professor, Health Management Research Center, Baqiyatallah University of Medical Sciences, Tehran, Iran. E-mail: bahadorihealth@gmail.com

Received August 2, 2017; Accepted August 15, 2017; Online Published August 29, 2017

\section{Dear Editor}

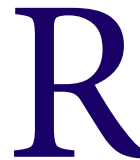

oad traffic accidents (RTA) are the thirdleading cause of death in Iran after coronary heart disease and stroke. ${ }^{1}$ Based on reports by the Iranian Legal Medicine Organization, RTA cause more than twenty thousand mortalities as well as eighty thousand major traumas each year in Iran. In 2010 alone, 22,974 Iranians lost their lives because of RTA (63 deaths per day on average). Moreover, 806,922 people had major trauma, and perhaps 4-5 times this number had minor traumas. ${ }^{2}$

The economic consequences of RTA in Iran are estimated to be between $\$ 7$ billion and $\$ 40$ billion US each year (2-4\% of Iran's GDP), depending on the method used to consider direct, indirect, and intangible costs. ${ }^{2-4}$ A significant part (35-50\%) of the cost of RTA in Iran is associated with productivity lost due to victims' premature mortality at young ages as well as survivors' permanent or long-term disabilities due to spinal cord trauma (SCT). ${ }^{2,5}$ The cost of hospitalization for each RTA patient is nearly 15 times greater than the cost of other patients, which is catastrophic for both patients and the healthcare system. ${ }^{6}$

Unfortunately, in spite of different plans, laws, and regulations in the country, the problem of RTA is still ongoing. However, there are important risk factors in this problem that should be known before any policy is made. RTA in Iran is more likely to occur for some socioeconomic groups at certain times and under certain circumstances. RTA mortality and morbidity are higher during Iran's national and religious holidays (such as the Nowruz festival or summer holidays). ${ }^{5}$ Fatal accidents occur more commonly after midnight. ${ }^{7}$ Males are 2-3 times more likely to be severely traumatized by RTA than females. ${ }^{7}$ Youths and uneducated people are responsible for most accidents and RTA mortalities in Iran. ${ }^{8}$ The mortality rate of uneducated people is 3 times higher than that of people with university degrees ${ }^{8}$. Moreover, there are some important environmental risk factors for RTA, including listening to music, using cell phones, fatigue and sleepiness, non-use of personal protective equipment (like seat belts and helmets) while driving, as well as bad road conditions and the use of non-equipped cars. $^{7}$

Neck and head traumas are the most common in RTA survivors, and poor pre-hospital care for such patients in Iran (including the lengthy and careless transport of SCT patients) is responsible for a considerable share of the long-term morbidities and production loss of survivors. While the first 60 minutes after RTA trauma - the "golden hour" - are vital for saving a victim's life, the mean pre-hospital time interval for such patients in Iran is about $37.2( \pm 17.2)$ minutes, which is too high. ${ }^{9}$ Rapid transportation of suburban RTA victims with helicopter Emergency Medical Service (EMS) can reduce the prehospital time, but such equipment is not available at a high enough rate in Iran. Finally, it should be noted that RTA is a multi-factorial phenomenon. In order to reduce the economic burden of this problem, policymakers should pay attention to all personal and environmental risk factors affecting the morbidity and mortality of RTA as well as the infrastructure reinforcement associated with RTA, such as the improvement of road conditions, car standards, and pre-hospital care services. All passengers over the age of 15 years should be thoroughly educated in first aid for RTA patients (i.e. cardiopulmonary resuscitation (CPR)). Traffic fines and penalties must be increased during Iran's national and religious holidays in order to be more dissuasive during peak accident times. Speed limitations should be revised according to the type of car (bus/SUV/sedan, etc.) and time (morning/ afternoon/night/middle of the night). Health insurance penalties must be determined to fine drivers and passengers who do not use personal protective equipment. Stricter safety standards should be

Copyright (C) 2017 The Author(s). This is an open-access article distributed under the terms of the Creative Commons Attribution License (http://creativecommons.org/licenses/by/4.0), which permits unrestricted use, distribution, and reproduction in any medium, provided the original work is properly cited. 
applied to vehicle traffic in Iran. More air ambulances should be provided for the timely rescue and transportation of suburban RTA cases in Iran.

\section{Authors' Contributions}

All authors contributed equally to this manuscript.

\section{Conflict of Interest Disclosures}

\section{No conflicts of interest.}

\section{Funding}

None.

\section{References}

1. Saadat S, Yousefifard M, Asady H, Moghadas Jafari A, Fayaz M, Hosseini M. The Most Important Causes of Death in Iranian Population; a Retrospective Cohort Study. Emerg (Tehran). 2015;3(1):16-21. pmid: 26512364.

2. Rezaei S, Arab M, Karami Matin B, Akbari Sari A. Extent, consequences and economic burden of road traffic crashes in Iran. J Inj Violence Res. 2014;6(2):57-63. doi: 10.5249/jivr.v6i2.191. pmid: 24045158.

3. Ainy E, Soori H, Ganjali M, Le H, Baghfalaki T. Estimating cost of road traffic injuries in Iran using willingness to pay (WTP) method. PLoS One. 2014;9(12):e112721. doi: 10.1371/journal.pone.0112721. pmid: 25438150.
4. Hasanzadeh J, Moradinazar M, Najafi F, Ahmadi-Jouybary T. Trends of Mortality of Road Traffic Accidents in Fars Province, Southern Iran, 2004 - 2010. Iran J Public Health. 2014;43(9):1259-65. pmid: 26175980.

5. Shams Vahdati S, GhafarZad A, Rahmani F, Panahi $F$, Omrani Rad A. Patterns of Road Traffic Accidents in North West of Iran during 2013 New Year Holidays: Complications and Casualties. Bull Emerg Trauma. 2014;2(2):82-5. pmid: 27162871.

6. Sargazi A, Sargazi A, Nadakkavukaran Jim PK, Danesh $\mathrm{H}_{\text {, }}$ Aval F, Kiani Z, et al. Economic Burden of Road Traffic Accidents; Report from a Single Center from South Eastern Iran. Bull Emerg Trauma. 2016;4(1):43-7. pmid: 27162926.

7. Sadeghi-Bazargani $\mathrm{H}$, Ayubi E, Azami-Aghdash S, Abedi L, Zemestani A, Amanati L, et al. Epidemiological Patterns of Road Traffic Crashes During the Last Two Decades in Iran: A Review of the Literature from 1996 to 2014. Arch Trauma Res. 2016;5(3):e32985. doi: 10.5812/atr.32985. pmid: 27800461.

8. Sami A, Moafian G, Najafi A, Aghabeigi MR, Yamini N, Heydari ST, et al. Educational level and age as contributing factors to road traffic accidents. Chin J Traumatol. 2013;16(5):281-5. pmid: 24103823.

9. Paravar M, Hosseinpour M, Salehi S, Mohammadzadeh M, Shojaee A, Akbari H, et al. Pre-hospital trauma care in road traffic accidents in kashan, iran. Arch Trauma Res. 2013;1(4):166-71. doi: 10.5812/atr.8780. pmid: 24396772.

Citation: Meskarpour Amiri M, Bahadori M, Mehrabi-Tavana A. The dilemma of road traffic accidents in Iran. Int J Med Rev. 2017;4(3):91-92. doi: 10.29252/ijmr-040307. 